\title{
Nanotechnology tools for antibacterial materials
}

The understanding of the interactions between biological systems and nanoengineered devices is crucial in several research fields, including tissue engineering, biomechanics, synthetic biology and biomedical devices. This review discusses the current knowledge of the interactions between bacteria and abiotic nanostructured substrates. First, the effects of randomly organized nanoscale topography on bacterial adhesion and persistence are described. Second, the interactions between microorganisms and highly organized/ordered micro- and nano-patterns are discussed. Finally, we survey the most promising approaches for the fabrication of silver polymeric nanocomposites, which have important applications as antimicrobial materials. The advantages, drawbacks and limitations of such nanotechnologies are critically discussed in view of potential future applications.

\section{KEYWORDS: bacterial adhesion biofilm nanotopography silver nanocomposites}

Bacterial surface contamination - the adhesion, persistence and colonization of surfaces by bacteria - is increasingly recognized as detrimental to health and society [1-4]. Besides impacting food safety, biofilm growth (arising from surface contamination) distresses economic sectors, such as sea transport (biofilms promote the binding of aquatic invertebrates onto the immersed sections of ships), manufacturing (biofilms stimulate corrosion processes) and health/medicine, leading to immense human and economic costs [1-9]. It is impossible to provide a universal description of bacterial biofilms. From a chemical point of view, biofilms consist of a complex mixture of exopolysaccharides, DNA and catalytic proteins, which are secreted by microorganisms after their adhesion onto surfaces, and whose biological functions are largely unknown [8,10-12]. Biologically, it represents an external digestive system that allows extracellular enzymes (secreted by bacteria) to localize in close proximity to cells, enabling the metabolization of the solid biopolymers present in the nearby environment [8]. From a physical point of view, a biofilm is form of slime matrix with specific robustness, viscosity and strength that varies depending on the particular strain of microorganism(s) and the specific environmental conditions [13-15]. Ecologically, biofilms represent the preferred niche where almost all bacteria live $[16,17]$; the evolutionary mechanisms led them to grow as a sessile adherent community, rather than as a dispersed, planktonic form. There is evidence of bacterial biofilm formation even in 3-billion-year-old African fossils [18], suggesting that such living forms promoted survival in the harsh environmental conditions of Earth at that time. From a genetic viewpoint, sessile bacteria have very different profiles of gene and protein expression, compared with their planktonic counterparts [19-22]. Hence, biofilms could represent a complex population of unicellular microorganisms that live, behave and interact with each other and the environment like a quasi-multicellular organism.

Figure 1 illustrates the most important features of biofilm formation, development and composition $[3,8]$. The most characterizing aspect of biofilms is, therefore, their 'heterogeneity' [19]. Another characteristic is the high durability in terms of resistance to mechanochemical or physical stress stimuli (i.e., UV radiation, antibiotic treatment and scraping). As such, it is widely accepted that the most effective way to prevent biofilm formation is a priori suppression of bacterial adhesion, rather than a posteriori chemical- or drug-based treatment. Great effort has been put into designing substrates that prevent the early stage of bacterial adhesion.

The main factors influencing bacterial adhesion are the physicochemical properties of the substrate material and microorganisms, and the environmental conditions [23-25]. Many investigations have focused on chemically modifying the abiotic surface to repel bacteria [26-30]. However, chemical modification has several drawbacks, such as reduced efficiency once the compounds/drugs are released, potential toxicity and the possible occurrence of local
Loris Rizzello ${ }^{1}$, Roberto Cingolani² \& Pier Paolo Pompa*1 ${ }^{1}$ Center for Bio-Molecular Nanotechnology, Istituto Italiano di Tecnologia, Via Barsanti, 1-73010 Arnesano (Lecce), Italy ${ }^{2}$ Istituto Italiano di Tecnologia, Central Research Laboratories, Via Morego, 30-16136 Genova, Italy *Author for correspondence: Tel.: +3908321816214 Fax: +3908321816230 


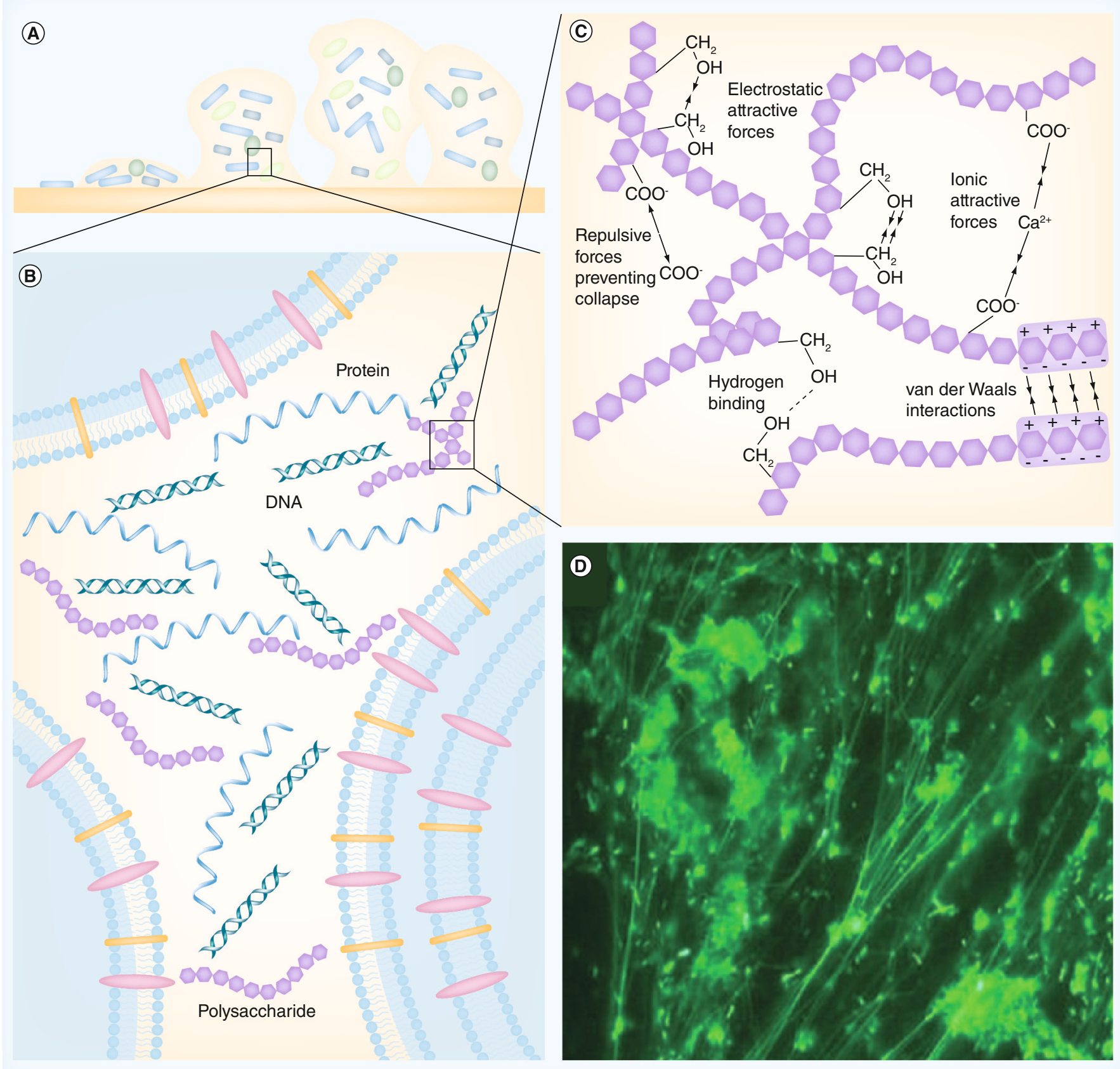

Figure 1. The complex extracellular polymeric substance produced by adherent bacteria. (A) Dynamic evolution, over time, of a bacterial biofilm onto abiotic substrates. After the adhesion of bacteria, the microcolonies start to divide and grow, and the biofilm matrix is secreted. During biofilm expansion, other environmental microorganisms can be involved and may became part of the colony, thus strengthening the overall community. At the same time, sessile bacteria can be dispersed throughout the surrounding surface.

(B) Principal components of the biofilm matrix: polysaccharides, proteins and DNA are distributed between the cells in a heterogeneous (and almost unique) pattern. (C) Classes of physicochemical interactions that regulate the stability of the extracellular polymeric substance matrix [115]. (D) SYTO9 staining of a biofilm produced by a 4-day-old culture of the $\gamma$-proteobacterium strain F8. Reproduced with permission from [8].

immunogenicity in vivo. It should also be considered that several anti-infective materials for medical use have been functionalized with antibiotics. This could contribute to the current spreading of antibiotic resistance, which is creating great concerns worldwide and making treatment of infection difficult [31-34]. Thus, recent attention has shifted toward exploiting surface topography. In this regard, nanotechnology offers new methods and techniques to design innovative surfaces with specific and highly controlled surface nanotextures.

The aim of this article is to provide a critical overview of the antibacterial effects of nanoderived 
substrates. The first section describes the effect of random nanoroughness on bacterial adhesion and persistence; the second section focuses on highly ordered micro- and nano-patterns; and the third section discusses silver polymeric nanocomposites (both synthetic and natural/bioinspired), a particularly promising class of antibacterial materials. For each topic, we critically address the limitations, especially from the biological standpoint, as well as discussing open issues and the future outlook.

\section{Effects of randomly organized nanotopography on bacterial adhesion}

Study of the relationship between surface roughness/porosity and bacterial adhesion traces back to the early 1980s, when it was mainly for dentistry and environmental applications [35-39]. Due to technological limitations, these studies were confined to examining antibacterial effects of poorly controlled random roughness. The biological investigations generally used colony-forming units assays, and direct counting under light or scanning electron microscopy to estimate the number of microorganisms attached to surfaces following incubation. Similar approaches were pursued into the 1990s, until nanotechnology was applied to study the bacteria-substrate interaction. In particular, Razatos and coworkers used the atomic force microscope (AFM) to analyze and quantify the initial events of bacterial adhesion with unprecedented resolution and precision [40]. They coated the AFM cantilever tip with a confluent layer of Escherichia coli, and then used the coated cantilevers to obtain force-distance curves describing the interaction forces between the bacteria and poly(methyl methacrylate)functionalized surfaces (Figure 2). By combining the high sensitivity of AFM with isogenic bacterial strains differing in cell surface composition (e.g., mutants expressing progressively truncated lipopolysaccharides), the authors were able to discriminate the contribution of specific cell surface components in the adhesion forces.

In addition to providing new characterization methods, nanotechnology provided improved nanometer-resolution fabrication techniques to control the size and shape of randomly organized nanorough surfaces. These techniques included plasma etching (based on reactive-ion etching), acid-mediated etching, anodic oxidation and controlled polymer coatings [41-43]. Many of these methods have been applied to explore the influence of surface roughness on bacterial adhesion.
In this framework, Bakker et al. studied bacterial adhesion on polyurethane-coated glass plates of varying elastic moduli and surface roughness. The authors found a direct relationship between the mean surface roughness and the attachment of micron-sized marine bacteria (Marinobacter hydrocarbonoclasticus, Psychrobacter sp. SW5H and Halomonas pacifica) by using multiple linear regression analyses [44]. Nanoroughness-dependent bacterial adhesion was confirmed in later studies [45-50], underscoring the importance of surface nanofeatures for adhesion. However, other works found the opposite trend, namely that a decrease in the topographical pattern (obtained by chemical etching) leads to an increase in the number of attached bacteria [51,52]. In addition, hydrophobic surfaces have been demonstrated to delay the adhesion of microorganisms when compared with hydrophilic substrates, which typically promote their attachment [53-55]. However, controversial results have also been reported [56]. Similar discrepancies also arose concerning the role played by surface energy on bacterial adhesion [57].

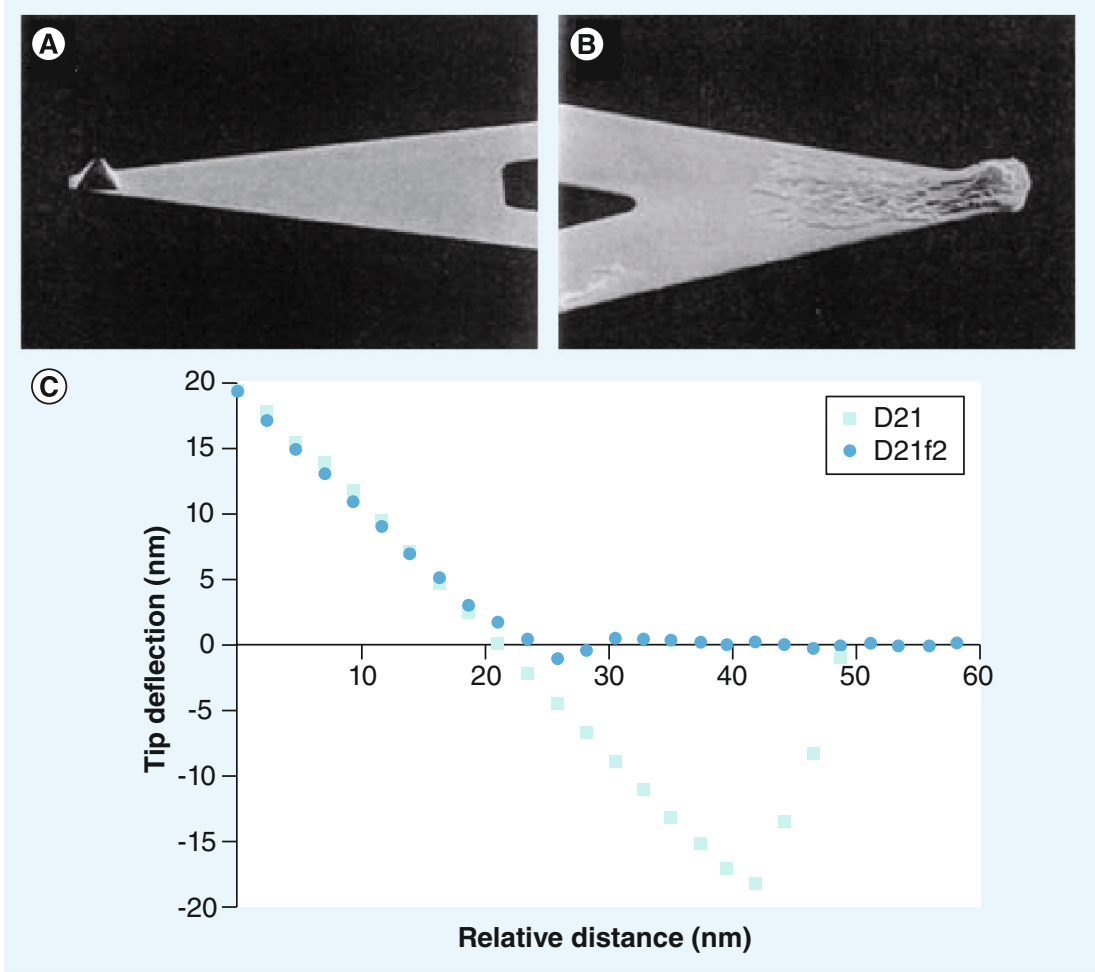

Figure 2. Atomic force microscope-based approach for probing the interaction forces between bacteria and abiotic surfaces. Scanning electron microscope images of (A) bare silicon nitride tip and (B) silicon nitride tip coated with Escherichia coli. (C) Average force curves between silicon nitride tips coated with two different $E$. coli (D21 and D21f2, which differ in the length of core lipopolysaccharide molecules) and glass spin-coated with poly(methyl methacrylate). Magnification: (A) 1800x and (B) 1500x.

Reproduced with permission from [40]. 
Although many studies have tried to define a general correlation between surface nanotopography and bacterial adhesion [58-62], a definitive explanation is still lacking. As recently suggested [25], this is probably due to the relatively crude approaches that have often been used to characterize surface nanotopographies. Accurate physicochemical characterization of a substrate requires a combination of nanometer-resolution surface methods, such as AFM, nanoindentation and scanning electron microscopy, together with elemental analyses, for example, energy dispersive $\mathrm{x}$-ray spectroscopy, time-of-flight secondaryion mass spectrometry and $\mathrm{x}$-ray photoelectron spectroscopy $[63,64]$. Furthermore, because of the intrinsically random organization of these surfaces, significant intra-sample and sampleto-sample variability may occur, thus requiring systematic investigations with higher statistical validity.

An additional limitation of past studies is the oversimplified description of microorganisms, which were treated as inert, perfectly smooth and geometrically regular colloidal microparticles, with surface properties and interaction dynamics estimated on purely theoretical grounds [65]. Although such assumptions were useful for examining the basic physicochemical interactions between abiotic surfaces and bacteria, they were inadequate for understanding the detailed aspects of the interaction. Additional important issues have to be taken into account. First, bacteria are rapidly evolving living systems that vary the protein composition of their cell envelope over time depending on environmental and physiological conditions [66], secrete proteins by specific secretory pathways [67], produce extracellular polymeric substance [68], and extend external organelles such as flagella and adhesive fimbriae [69]. Second, microorganisms have heterogeneous shapes and sizes. For example, the Streptococcus species (S. pneumoniae, S. pyogenes and S. oralis) and Staphilococcus spcies (S. aureus, S. epidermidis and $S$. haemolyticus) have a spherical shape, but other microorganisms possess a bacillus ( $\mu$-rod) profile (e.g., Bacillus subtilis or Bacillus cereus), or even a more complex spiral shape (Spirochetes) (Figure 3). Third, the bacterial growth conditions, such as incubation time, characteristics of the growth medium (e.g., ionic strength), temperature and physical agitation during incubation, also affect the interaction at the interface. For these reasons, simplistic topological and physicochemical models for the bacteria and surfaces are inadequate to reliably predict the relationships between nanotopography and bacterial adhesion.
Another important issue in this research field is the biological characterization of the interaction events, since most experimental approaches are based on the observation of morphological changes (assessed by scanning electron microscopy, transmission electron microscopy and confocal/fluorescence microscopy), or on counting and viability assays. However, these approaches generally do not take into account the detailed molecular events accompanying the bacteria-substrate interactions. In this framework, we recently uncovered specific changes in the genomic and proteomic profile of E. coli adhering onto flat (control) and nanorough surfaces, which were produced by a spontaneous Galvanic displacement reaction [70-73] (Figure 4). We found that $E$. coli adhered to nanostructured surfaces undergo genetic phase variation of fimbrial subunit expression (the fimbrial operon was switched 'off', due to the overexpression of the LrhA repressor and upregulation of the FimE recombinase), as well as general stress conditions (suggested by the activation of the two-component system CpxP/R pathway). Furthermore, by proteomic analyses, we detected 15 proteins (involved in biosynthesis, peptide transport, metabolic pathways and DNA repair) that were differently regulated in bacteria growing on nanorough versus smooth surfaces.

In summary, despite the large body of literature on the topic, the question of whether antibacterial substrates should be designed with nanostructured or flat features remains unresolved, and will require more systematic investigations. Future efforts should be directed toward fine fabrication methods, high-resolution physicochemical characterization of surfaces, and deeper biochemical and molecular biology investigations of bacteria-surface interactions.

\section{Effects of regular nanopatterns on bacterial adhesion}

As outlined above, there have been many studies on bacterial adhesion to randomly nanorough surfaces, because these surfaces do not require complex fabrication methods. However, bacterial adhesion onto highly regular patterned surfaces has not been extensively studied until recently, with the advent of well-controlled, reproducible nanopatterning techniques. Several nanoscale surface patterning methods have been improved, including photolithography [74], nanoimprint lithography [75], colloidal and E-beam lithography [76], anodic oxidation of metallic surfaces [77], $\mu$-contact printing [78] and dip-pen nanolithography [79]. Consequently, 


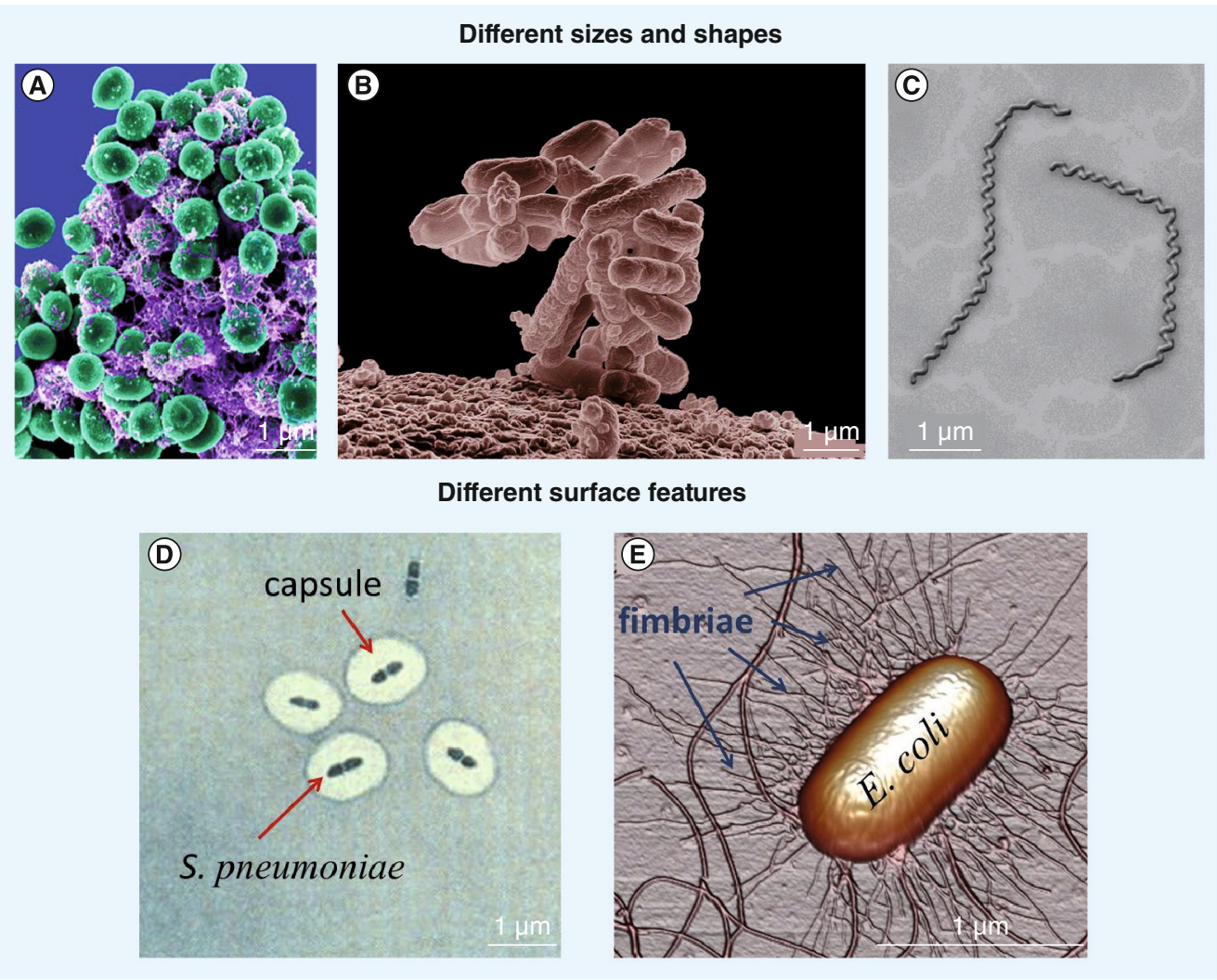

Figure 3. The complex sizes, shapes and surface features characterizing microorganisms. (A) The spherical shape of Staphylococcus epidermidis. (B) The rod-like structure of E. coli. (C) The spiral shape of leptospires. (D) The polysaccharide capsule of S. pneumoniae avoids bacterial clearance performed by host cells, since the bacterial antigens are hidden to both immunoglobulin proteins and phagocytic cell lines, such as macrophages. (E) The adhesive organelles' type 1 fimbriae allow bacteria to adhere to both host tissues and abiotic surfaces, thus starting the colonization processes, and biofilm formation and development.

E. coli: Escherichia coli; S. pneumoniae: Streptococcus pneumoniae.

(A) Image courtesy of the National Institute of Allergy and Infectious Diseases.

(C) Reproduced with permission from [201].

(D) Image courtesy of the CDC.

(E) Image courtesy of the Texas Department of State Health Services (TX, USA).

different patterns, such as ordered stripes, pits, pillars, squares and grooves, have been fabricated to create antibacterial and antibiofouling surfaces.

Recently, self-assembled monolayers (SAMs) presenting three functional groups, methyl, L-gulonamide (a sugar alcohol tethered with an amide bond) and tri(ethylene glycol) (TEG), have been used to explore E. coli adhesion and biofilm growth [80]. Unpatterned TEG-terminated SAMs were the only ones able to suppress E. coli biofilm formation compared with bare gold surface. Substrates were then patterned by microcontact printing with $50 \times 50 \mu \mathrm{m}$ square areas consisting of methyl-terminated SAMs surrounded by TEG-terminated SAMs. Biofilms could grow and develop on the methyl-terminated patterns, but not on the TEG regions. The authors also found that adding free TEG molecules to the bacterial culture media caused general inhibition of biofilm formation. Overall, the biofilm reduction was demonstrated to be the result of multiple factors, including the chemorepellent nature of TEG, its inhibitory effect on cell mobility and the solvent structure at the interface.

Polydimethylsiloxane surfaces, with protruding square features, have also been tested for their ability to prevent adhesion of fluorescent $E$. coli cells and to inhibit biofilm formation and development [81]. Patterned polydimethylsiloxane surfaces, prepared by a combination of silicon wafer etching and photolithography, consisted of $10-\mu \mathrm{m}$ tall ordered squares; both the lateral dimensions of the square patterns (in the $2-100 \mu \mathrm{m}$ range) and the pattern periodicity (in the $5-20 \mu \mathrm{m}$ range) were systematically varied. The authors found that bacteria preferentially adhered, and formed biofilms, in the valleys between the protruding features, even when the dimensions of the 


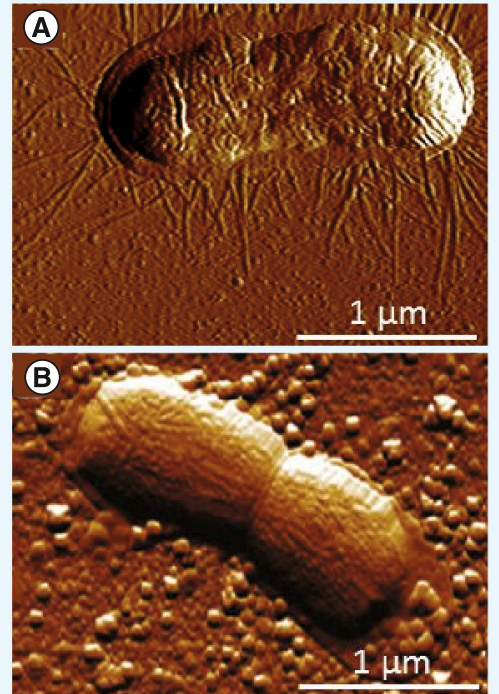

(D)
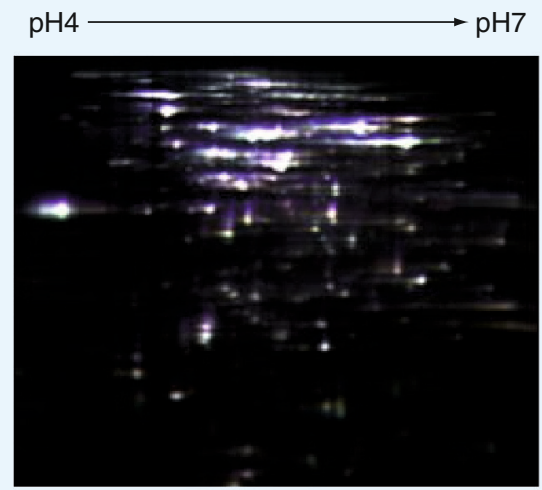

(

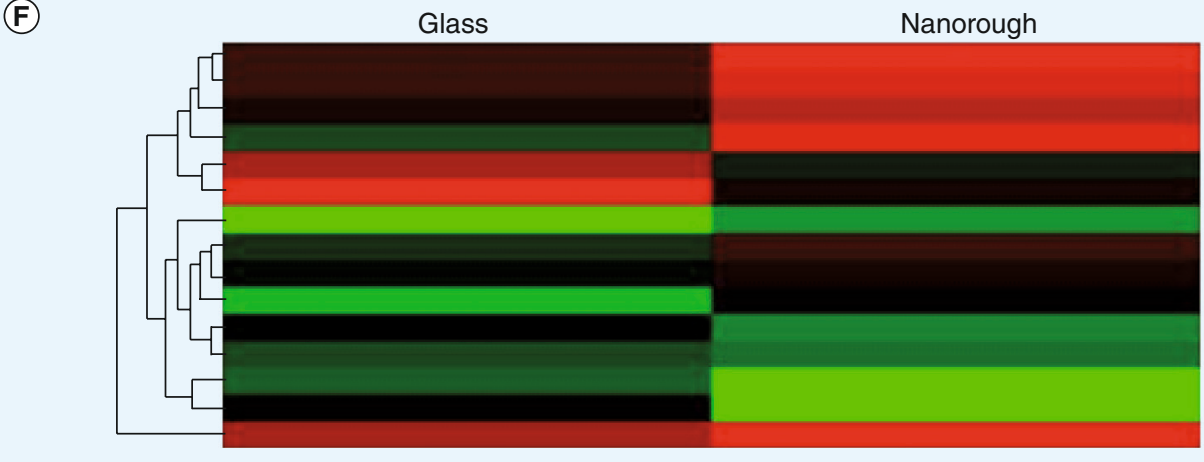

Glass
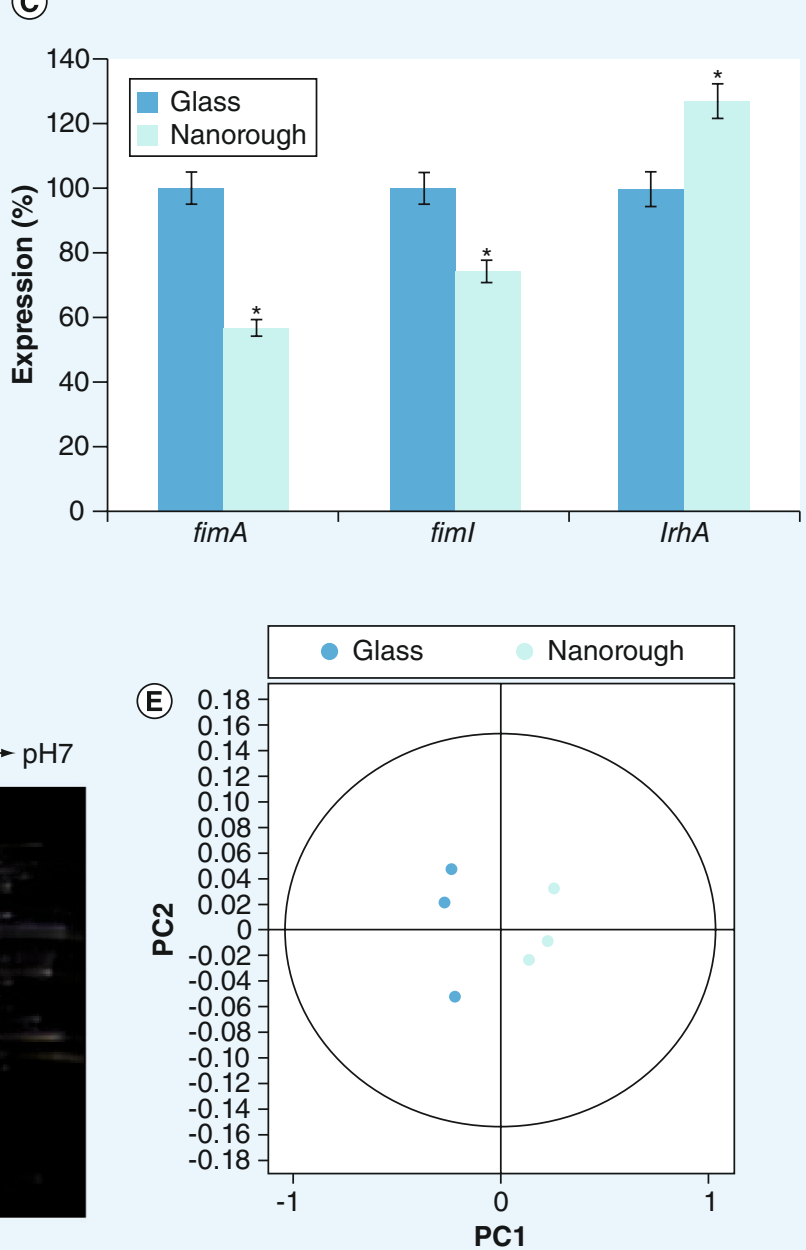

(1)

47
658
56
1220
155
157
11
43
482
220
913
1127
1080
1235
1060

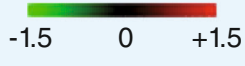

Figure 4. Molecular response of Escherichia coli adhering onto flat and nanorough gold surfaces. Bacteria were grown on (A) flat and (B) nanorough gold substrates. The nanostructured surfaces led Escherichia coli cells to repress the expression of the adhesive organelles' type 1 fimbriae. (C) Expression levels of fimbrial gene subunits in the treated bacteria (growing onto nanorough surfaces) compared with control bacteria (growing on flat surfaces). (D-F) Global protein expression profile by means of 2D-difference gel electrophoresis proteomic assays. (D) Fluorescent staining of a 2D gel and (E) PC analyses for analyzing the statistical populations of up- and down-regulated proteins. (F) The electrophoresis proteomic assay shows a trend for down- (green) and up-regulation (red) of proteins for flat and nanorough samples.

PC: Principal component.

Reproduced with permission from [70]. 
plateaus (the top of the squares) were significantly larger than the dimensions of the valleys. They also performed experiments combining the effects of features size and gravitational force (by incubating bacteria in upright vs inverted configurations), observing that, although gravity does facilitate adhesion of bacteria, there is a threshold size of the surface patterns that governs biofilm formation and development.

Another study examined the interaction of Pseudomonas aeruginosa, B. subtilis and E. coli with nanometer-scale periodic surface features (pillars $300 \mathrm{~nm}$ in diameter and $2 \mu \mathrm{m}$ in height) with different spatial arrangements, obtained by combining fast replication molding techniques with sputtering of PtPd or AuPd [82]. The authors found that bacterial attachment and orientation at the single-cell level is modulated by the nanofeatures: both Gram-positive and Gram-negative bacteria spontaneously oriented themselves according to the direction of the pattern geometries. These results suggest that appropriate patterning could finely control the 3D spatial segregation of single bacteria and interbacteria communication, thus affecting the natural biofilm organization (FIGURE 5).
(A)
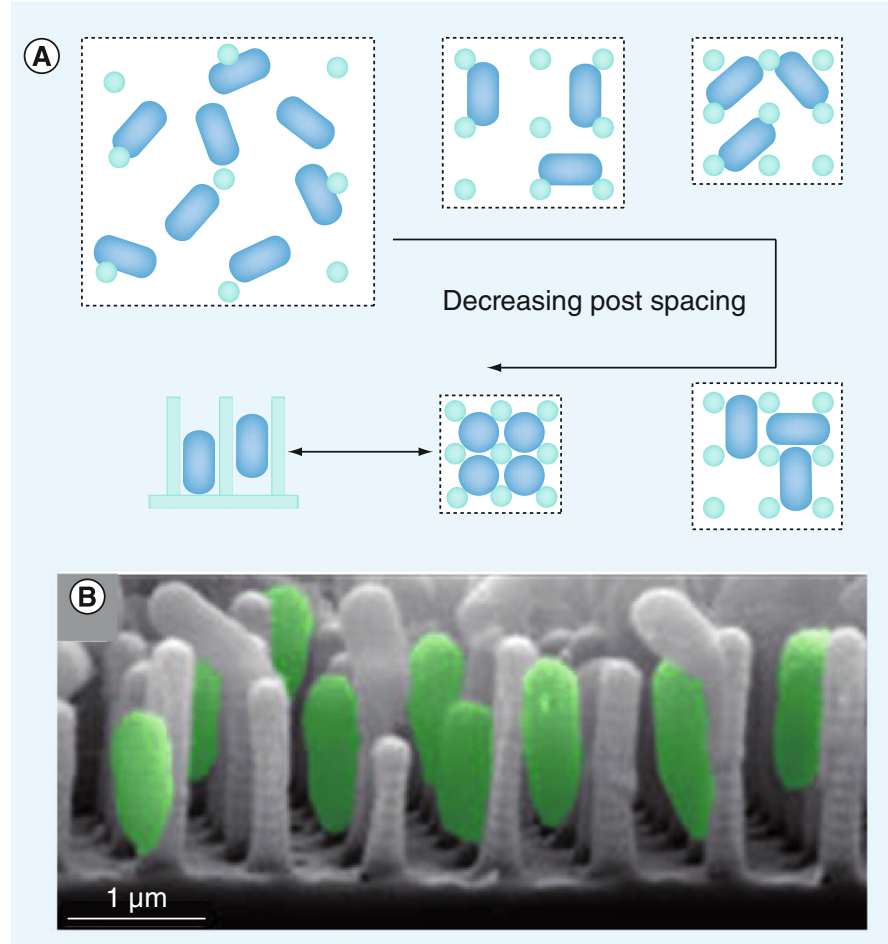

The role of ordered surface structures in affecting bacterial retention was also investigated by Whitehead and coworkers [45]. The authors incubated several unrelated microorganisms of different sizes (S. aureus, P. aeruginosa and Candida albicans) on substrates with pores of different diameters $(0.2,0.5,1$ and $2 \mu \mathrm{m})$, obtained by combining magnetron sputtering with a template technique. Using microbial retention assays, they found that $S$. aureus and $P$. aeruginosa $(\sim 1 \mu \mathrm{m}$ in diameter) tended to be retained in the largest $(2 \mu \mathrm{m})$ surface pores, but not between pores. At the same time, $C$. albicans $(\sim 5 \mathrm{~m}$ in diameter) was uniformly distributed across the porous surface. This suggests that the dimension of the surface features relative to the size of the cells is important for bacterial retention.

With regard to relative dimensions, the work of Díaz and collaborators is of particular interest [83]. The authors used AFM to examine the response of Pseudomonas fluorescens to patterned gold surface with submicron trenches and unpatterned gold surfaces with random orientation. They found that the bacterial flagella tended to align towards neighboring cells, apparently interconnecting them (Figure 6). The
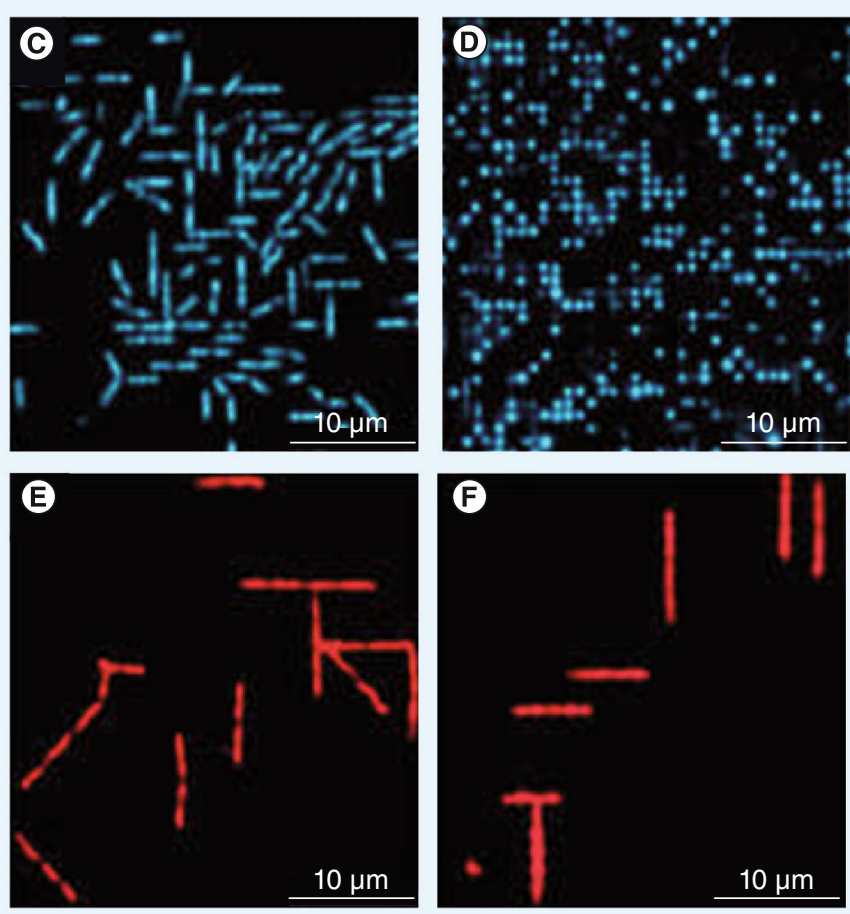

Figure 5. Ordered surface geometries guide bacterial adherence and their spatial patterning. (A) The adhesion patterns of rod-like bacteria on the pillar arrays. As the post spacing decreases, bacteria can increase their contact area by adhering to the increasing number of pillars, with abnormal orientation relative to the substrate. In the most densely packed state, cells orient themselves normal to the substrate to maximize their contact with the posts. (B) Cross-sectional scanning electron microscope image of bacteria cultured on periodically structured surfaces. Spontaneous assembly of (C \& D) Bacillus subtilis and (E \& F) Escherichia coli cultured on these surfaces. The pillar spacing is wider in (C \& E) than (D \& F).

Reproduced with permission from [82]. 
authors interpreted this behavior as flagellamediated signaling between bacteria. If so, the signaling depended on the size of the pattern. Small striped patterns improved the flagellamediated interbacteria communication, thus presumably facilitating the early stages of biofilm formation [83]. Bigger stripes could spatially prevent bacterial communication, thus delaying biofilm development.

Other research has demonstrated the possibility to manipulate individual bacterial cells, and their immediate extracellular environments, by exploiting specific ordered micrometer and submicrometer structures fabricated by soft lithography approaches [84]. These latter results are likely to be of crucial importance for the design of cell chips based on ordered arrays of bacteria.

In summary, these combined findings highlight that ordered surface nanopatterns have an important effect on bacterial adhesion and
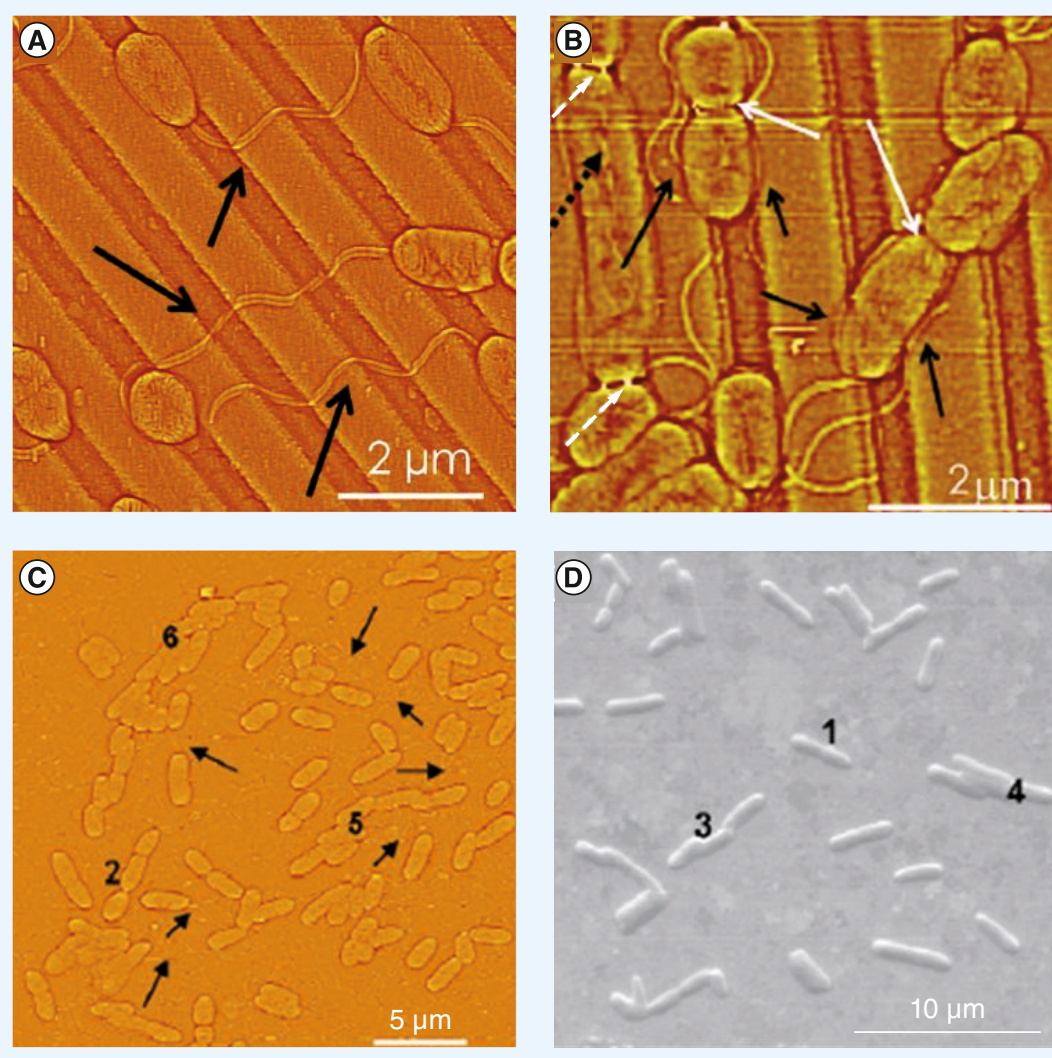

Figure 6. Correlation between flagella orientation and surface geometries. (A \& B) Contact atomic force microscope images of Pseudomonas fluorescens attached to patterned gold substrates. The black arrows indicate flagella surrounding microorganisms or oriented towards neighboring bacteria, the white arrows show bacterial division, the dashed white arrows indicate the presence of pili connecting cells and the dotted black arrow indicates an elongated bacterium. (C) Atomic force and (D) scanning electron microscope images of $P$. fluorescens growing onto unpatterned gold substrates. Arrows display groups of flagella oriented towards other cells. Numbers indicate the different stages of formation of a raft-like structure. Reproduced with permission from [83]. retention. Nanopillars, surface valleys and edges of grooves seem to protect bacteria from external perturbations that would otherwise tend to detach them from the substrate [45,85]. Moreover, surface patterns of a size comparable to bacteria seem to effectively host microorganisms and facilitate cellular intercommunication, thus promoting biofilm formation and development. However, for ordered nanopatterns, a direct correlation between pattern size and bacterial adhesion has not been clearly demonstrated, similar to the case of random nanopatterns. This uncertainty probably arises from strain-specific bacterial responses to external physical stimuli, as well as from some limitations of the biological assays. In our opinion, further systematic investigations should address the molecular mechanisms of bacteria-patterned substrate interactions in terms of regulation of both global and specific molecular pathways. Bacteria possess several molecular and mechanochemical sensor systems along with finely controlled intracellular signaling pathways, but little is known about how these systems respond to interactions with substrate patterns. Understanding how bacteria sense specific surface features (e.g., pits, grooves, squares, holes and stripes) and how they respond to those features (e.g., activation of signaling pathways) could lead to the design of a new generation of surfaces that avoid bacterial persistence, due to their intrinsic antifouling properties, and affect specific microbial responses to achieve the desired biological properties.

\section{Silver-based nanocomposites \& their antibacterial characteristics}

This section discusses strategies to fabricate antibacterial substrates based on the use of silver polymeric nanocomposites as advanced antimicrobial agents. Although it has been known for centuries that silver compounds impede the growth of microorganisms (during the Roman empire liquids were stored in silver water bags) [86-88], the recent improvement of 'bottom-up' approaches in nanofabrication techniques has enabled the realization of highly controlled nanocomposites functionalized with silver nanoparticles (AgNPs). In particular, a great variety of hydrogel matrices based on natural polymers or their derivatives (e.g., gelatin, starch, chitosan, cellulose and sodium alginate), along with synthetic polymers (polyvinyl alcohol and polyvinyl pyrollidone), have been developed and combined with AgNPs [89-95].

AgNPs elicit bactericidal effects mainly through the release of $\mathrm{Ag}^{+}$ions from their surfaces. 
In particular, $\mathrm{Ag}^{+}$may induce direct membrane damage, leading to dissipation of proton motive force and depletion of intracellular ATP levels [96-99]. The toxic effects of AgNPs on microorganisms have been also ascribed to $\mathrm{Ag}^{+}$ionrelated reactive oxygen species production, free radicals that may damage both lipids and DNA [100-102].

A common method to fabricate AgNPfunctionalized polymer matrices consists of entrapping $\mathrm{Ag}^{+}$cations within the chains of the polymers, followed by reduction with common reducing agents. Such an in situ approach has two main advantages over simple mixing of the presynthesized AgNPs with the polymer precursors: the macromolecular chains of polymers improve the dispersion of NPs and avoid aggregation phenomena; and the physicochemical properties of the polymer chains determine the size distribution and shape of the AgNPs.

Among the available synthetic polymers, polyurethanes are materials of choice because they can be applied to furniture, textiles, adhesives and biomedicine [103]. Shah and collaborators, for example, functionalized polyethylene glycol (PEG)-polyurethane-TiO, with AgNPs, and found excellent activity against both $B$. subtilis and $E$. coli [104]. An interesting aspect of this work is the facilitated photoreduction of silver nitrate to AgNPs within the polymer matrix, induced by the presence of $\mathrm{TiO}_{2}$.

Other approaches to making AgNP composites have used synthetic polymers such as poly(methyl methacrylate) and the polyetherbased thermoplastic aliphatic polyurethanes [105]. These composites also exhibit excellent broad-spectrum antimicrobial behavior against Gram-positive and Gram-negative bacteria, and even fungi (e.g., C. albicans, Aspergillus niger, and Saccharomyces cerevisiae) [105].

Research has also focused on the use of biopolymers - polymers normally available in nature - or biomimicking polymers, because of their low cost, biocompatibility and wide availability [106]. For example, Fullenkamp and collaborators synthesized water-soluble PEG polymers containing reactive catechol moieties, inspired by the adhesive proteins of natural mussels [107]. The authors employed silver nitrate to oxidize the catechols of the PEG polymers, leading to covalent crosslinking and hydrogel formation with the simultaneous reduction of $\operatorname{Ag}(\mathrm{I})$. These substrates were found to release silver constantly for at least 2 weeks in phosphate-buffered saline solution, thus inhibiting bacterial growth. Mammalian cell viability was unaffected, however, due to the overall low concentration of $\mathrm{Ag}^{+}$ions.

Gelatin hydrogel pads loaded with AgNPs have also been developed for antibacterial wound dressings [108]. The pads were prepared by the solvent-casting technique from a gelatin aqueous solution containing $\mathrm{AgNO}_{3}$ and were aged for different periods and then crosslinked with glutaraldehyde. After $24 \mathrm{~h}$ of incubation in phosphate-buffered saline or simulated body fluid, silver release of approximately $50 \%$ and $60 \%$ was detected, respectively. Colonyforming units assays indicated that these pads were effective against $S$. aureus, $E$. coli and $P$. aeruginosa, with almost complete inhibition of bacterial growth [108].

In another approach, Bayer and collaborators developed a method to functionalize cellulose with ethyl cyanoacrylate nanocomposite shells [109]. In particular, they were able to surround cellulose fibers of paper sheets with different nanomaterials, such as submicrometer wax particles or polytetrafluoroethylene particles (to make paper superhydophobic), $\mathrm{MnFe}_{2} \mathrm{O}_{4}$ nanoparticles (to make paper magnetic), $\mathrm{CdSe} / \mathrm{ZnS}$ quantum dots (to make paper fluorescent) and AgNPs (to make paper antibacterial) (Figure 7) [109]. The advantage of this technique is that it can be applied postproduction to a wide range of fiber-based materials, from paper to fabrics, leaving the original properties of the material unaffected (e.g., printability, consistency and touch).

Finally, we would like to drive the reader's attention to cellulose matrices, which represent an important class of nature-derived polymers [110-114]. Similar to synthetic polymer chains, carbohydrates may act as a template for the entrapment of $\mathrm{Ag}^{+}$cations (through their carboxylate units), while the final reduction to AgNPs is usually mediated by various reducing agents.

In conclusion, synthetic polymers have advantages in the overall flexibility of the fabrication process, but they may have some limitations. In particular, they could release some of their components, resulting in long-term toxic effects in the host organisms. In addition, synthetic nanocomposites could have limited biocompatibility, leading to inflammation phenomena and even hazardous immunogenic responses. Such drawbacks are partly solved by using natural or bioinspired polymers. However, the complicated organic reactions and need for large quantities of reducing agents are significant limitations in their use. Furthermore, 

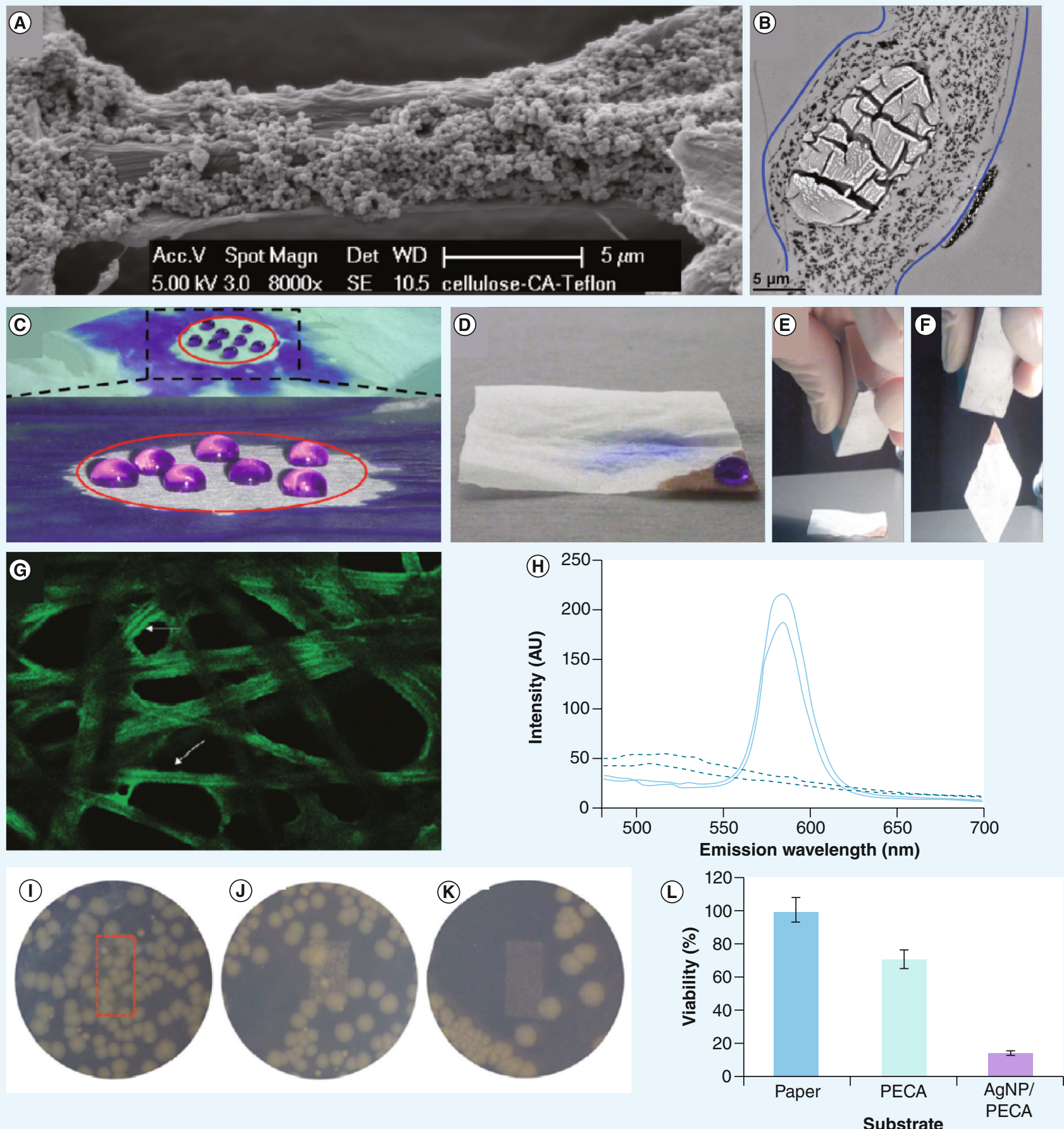

Figure 7. Cellulose fiber networks with multifunctional properties. (A) Scanning electron microscope image showing the surface of a cellulose fiber roughened by polytetrafluoroethylene particles mixed with PECA. (B) Cross-sectional transmission electron microscope image of a cellulose fiber embedded in a shell of the $\mathrm{MnFe}_{2} \mathrm{O}_{4}$ nanoparticle/PECA composite. (C) Colored water droplets stay on the surface of a cellulose sheet treated with PECA (circled), whereas they are completely absorbed in the untreated area. (D) Photo showing the difference in the wetting properties between the corner of a sheet treated with the nanocomposite of 5.0 wt $\% \mathrm{MnFe}_{2} \mathrm{O}_{4}$ nanoparticles in PECA (hydrophobic) and the untreated inherently hydrophilic part. (E \& F) Magnetic actuation of the treated sheet. (G) Confocal microscope image showing emission from a cellulose sheet after treatment with the quantum dot/PECA nanocomposite. (H) Characteristic emission spectra of the quantum dots identified on the fibers coated with CdSe/ZnS quantum dot/PECA nanocomposite (solid lines) shown by white arrows in (G), compared with the low intensity and broad emission of selected pure cellulosic sheets or cellulosic sheets only treated with PECA (dotted lines). (I-L) Antibacterial effect after treatment of cellulose sheets with AgNP/PECA nanocomposites against Escherichia coli: (I) control, (J) PECA- and (K) AgNP/PECA-treated sheets. (L) Quantitative analysis of the population of bacteria grown on PECA- and AgNP/PECA-treated sheets compared with control samples.

AgNP: Silver nanoparticle; PECA: Poly(ethyl-2-cyanoacrylate).

Adapted with permission from [109]. 
most of the synthetic routes employ chemical reduction techniques for AgNPs (e.g., sodium borohydrate, dimethyl formamide, hydrazine hydrate and ethylene glycol) that could be toxic or hazardous. In this respect, the incorporation of nanoparticles into polymeric hydrogel matrices, by using in situ photoreduction methods, is one of the most promising strategies. In addition, the development of postproduction approaches could be an enormous advantage for industrial applications.

\section{Conclusion \& future perspective}

This review discussed recent advances in microand nano-technologies for suppression of bacterial growth. The adhesion of bacteria onto abiotic substrates is, in fact, the starting point of chronic biofilm-associated contamination and infections, which are exceedingly difficult to remove using commercially available drugs. Deeper insight into the physicochemical and biological aspects of the interaction between prokaryotes and nanoengineered substrates is strongly needed in the next 5-10 years, to develop new approaches that may avoid bacterial persistence and, thus, inhibit bacterial biofilm development. Nanotechnology will provide important tools for designing and fabricating a new generation of substrates with specific antimicrobial properties.

Despite the promise of nanoengineered antibacterial surfaces, the literature available to date does not point to clear-cut or general conclusions about the interactions between bacterial adhesion and surface topology (nanoroughness), nor does it provide a clear explanation of the underlying biological mechanisms for the interactions. Generalized assumptions about the biology of surface-bacteria interactions have proven to be inadequate. In fact the available data suggest a highly strain-dependent biological response in most experiments. The data on interactions between microorganisms and ordered/organized nanopatterns have been similarly divergent, hindering development of a general model. However, continued progress in nanopatterning methods should lead to a better understanding of the relationship between the physicochemical properties of the substrate and bacterial adhesion, although a lot of work still needs to be carried out to develop a general

\section{Executive summary}

\section{Background}

- Bacteria adhering onto surfaces start to colonize and grow in a hydrated 3D polymeric matrix of their own synthesis, forming biofilms. This living condition enables microorganisms to resist hard stress stimuli (i.e., UV irradiation, high temperature and antibiotic treatment), and to behave like a quasi-multicellular organism.

Biofilms distress several economic sectors and represent the cause of chronic infections, especially in patients with medical implants.

- The most effective strategy to counteract biofilm formation is the suppression of the early-stage adhesion event of bacteria, rather than a posteriori chemical- or drug-based therapy. This may be obtained by modifying the physicochemical parameters of the target surfaces.

- While chemical modification of substrates may have some limitations, the engineering of surface nanotopography or the development of silver nanoparticle-based nanocomposites provide new tools to prevent bacterial adhesion.

\section{Effects of randomly organized nanotopography on bacterial adhesion}

- Surface nanoroughness has been demonstrated to affect the adhesion and retention of bacteria, although contrasting data have been reported.

- The lack of definitive understanding is probably due to the relatively crude approaches that have often been used to characterize surface nanotopographies, the oversimplified description of microorganisms and the need for deeper biological characterization of the interaction events.

\section{Effects of regular nanopatterns on bacterial adhesion}

- Highly ordered surface nanopatterns have been found to strongly affect bacterial adhesion and retention: nanopillars; surface valleys; and edges of grooves seem to protect bacteria from external perturbations.

- Surface patterns with a size comparable to bacteria may host microorganisms and facilitate cellular intercommunication, promoting biofilm formation and development.

- As in the case of random nanopatterns, a direct correlation between pattern size and bacterial adhesion has not been clearly demonstrated. This is also because of strain-specific bacterial responses to external physical stimuli.

\section{Antibacterial characteristics of silver nanoparticle-based nanocomposites}

- Silver-based nanocomposites seem to be an effective tool in eliciting strong antibacterial effects.

- Synthetic Ag-based polymers can be easily fabricated with rather inexpensive procedures. However, there are some concerns related to their biocompatibility.

Biopolymers (synthesized with polymers available in nature or with biomimicking polymers) may overcome the biocompatibility issue of synthetic polymers, but their synthesis processes are more complicated. 
model for these phenomena. By contrast, the data on the biological applications of silver polymeric nanocomposites seem to be rather consistent. AgNP-functionalized polymers have attracted considerable interest, due to their broad-spectrum antimicrobial characteristics as well as their tunable morphologies, uniformity, chemical composition and architecture. Naturally inspired polymers carrying AgNPs seem to be the most promising substrates, due to their superior biocompatibility compared with their synthetic counterparts. At the same time, smart postproduction modifications, carried out by combining several nanomaterials, represent an intriguing new approach for the realization of innovative, multipurpose materials. However, there are still several important open questions, especially in the understanding

\section{References}

Papers of special note have been highlighted as:

"n of considerable interest

1 Davey ME, O’Toole GA. Microbial biofilms: from ecology to molecular genetics. Microbiol. Mol. Biol. Rev. 64(4), 847-867 (2000).

2 de Nys R, Steinberg PD. Linking marine biology and biotechnology. Curr. Opin. Biotechnol. 13(3), 244-248 (2002).

3 Hall-Stoodley L, Costerton JW, Stoodley P. Bacterial biofilms: from the natural environment to infectious diseases. Nat. Rev. Microbiol. 2(2), 95-108 (2004).

II- Describes the dynamic behavior of biofilms and their propagative mechanisms in both the natural environment and infectious diseases.

4 Costerton JW, Montanaro L, Arciola CR. Bacterial communications in implant infections: a target for an intelligence war. Int. J. Artif. Organs 30 (9), 757-763 (2007).

5 Callow ME, Callow JA. Substratum location and zoospore behavior in the fouling alga Enteromorpha. Biofouling 15(1-3), 49-56 (2000).

6 Qian PY, Lau SC, Dahms HU, Dobretsov S, Harder T. Marine biofilms as mediators of colonization by marine macroorganisms: implications for antifouling and aquaculture. Mar. Biotechnol. (NY) 9(4), 399-410 (2007).

7 Chew BH, Lange D. Ureteral stent symptoms and associated infections: a biomaterials perspective. Nat. Rev. Urol. 6(8), 440-448 (2009).

8 Flemming HC, Wingender J. The biofilm matrix. Nat. Rev. Microbiol. 8(9), 623-633 (2010).

- Describes the functions, properties and constituents of the extracellular polymeric substances that make biofilms the most successful forms of life on earth.

9 Callow JA, Callow ME. Trends in the development of environmentally friendly fouling-resistant marine coatings. Nat. Commun. 2, 244 (2011).

$10 \mathrm{Ma}$ L, Conover M, Lu H et al. Assembly and development of the Pseudomonas aeruginosa biofilm matrix. PLoS Pathog. 5(3), e1000354 (2009).

11 Gotz F. Staphylococcus and biofilms. Mol. Microbiol. 43(6), 1367-1378 (2002).

12 Skillman LC, Sutherland IW, Jones MV. The role of exopolysaccharides in dual species biofilm development. J. Appl. Microbiol. 85(Suppl. 1), 13S-18S (1998).

13 Sutherland IW. The biofilm matrix - an immobilized but dynamic microbial environment. Trends Microbiol. 9(5), 222-227 (2001).

14 Sutherland IW. Exopolysaccharides in biofilms, flocks and related structures. Water Sci. Technol. 43(6), 77-86 (2001).

15 Donlan RM. Biofilms: microbial life on surfaces. Emerg. Infect. Dis. 8(9), 881-890 (2002).

16 Decho AW, Kawaguchi T. Confocal imaging of in situ natural microbial communities and their extracellular polymeric secretions using Nanoplast resin. Biotechniques 27(6), 1246-1252 (1999)

17 Flemming HCW. Encyclopedia of Environmental Microbiology. Wiley, NY, USA, 1223-1231 (2002).

18 Rasmussen B. Filamentous microfossils in a 3,235-million-year-old volcanogenic massive sulphide deposit. Nature 405 (6787), 676-679 (2000). of the actual mechanisms of antibacterial action of $\mathrm{AgNPs}$ and their possible toxicity to eukaryotic cells. Future efforts should also be directed toward an overall improvement of the efficiency of nanocomposites, since the controlled, long-term release of $\mathrm{Ag}^{+}$ions is important for real applications in implant devices.

\section{Financial \& competing interests disclosure}

The authors have no relevant affiliations or financial involvement with any organization or entity with a financial interest in or financial conflict with the subject matter or materials discussed in the manuscript. This includes employment, consultancies, honoraria, stock ownership or options, expert testimony, grants or patents received or pending, or royalties.

No writing assistance was utilized in the production of this manuscript.

19 Beloin C, Ghigo JM. Finding gene-expression patterns in bacterial biofilms. Trends Microbiol. 13(1), 16-19 (2005).

20 Schembri MA, Kjaergaard K, Klemm P. Global gene expression in Escherichia coli biofilms. Mol. Microbiol. 48(1), 253-267 (2003).

21 O’Toole G, Kaplan HB, Kolter R. Biofilm formation as microbial development. Annu. Rev. Microbiol. 54, 49-79 (2000).

22 Sauer K. The genomics and proteomics of biofilm formation. Genome Biol. 4(6), 219 (2003).

23 Busscher HJ, Norde W, Sharma PK, van der Mei HC. Interfacial re-arrangement in initial microbial adhesion to surfaces. Curr. Opin. Colloid Interface Sci. 15(6), 510-517 (2010).

24 Ubbink J, Schär-Zammaretti P. Colloidal properties and specific interactions of bacterial surfaces. Curr. Opin. Colloid Interface Sci. 12(4-5), 263-270 (2007).

25 Crawford RJ, Webb HK, Truong VK, Hasan J, Ivanova EP. Surface topographical factors influencing bacterial attachment. Adv. Colloid Interface Sci. 179-182(0), 142-149 (2012).

26 Emerson, Bergstrom TS, Liu Y et al. Microscale correlation between surface chemistry, texture, and the adhesive strength of Staphylococcus epidermidis. Langmuir 22(26), 11311-11321 (2006).

27 Mackintosh EE, Patel JD, Marchant RE, Anderson JM. Effects of biomaterial surface chemistry on the adhesion and biofilm formation of Staphylococcus epidermidis in vitro. J. Biomed. Mater. Res. A 78(4), 836-842 (2006).

28 Etienne O, Picart C, Taddei C et al. Multilayer polyelectrolyte films functionalized by insertion of defensin: a new 
approach to protection of implants from bacterial colonization. Antimicrob. Agents. Chemother. 48(10), 3662-3669 (2004).

29 Kowalczuk D, Ginalska G, Golus J. Characterization of the developed antimicrobial urological catheters. Int. J. Pharm. 402(1-2), 175-183 (2010).

30 Parreira P, Magalhaes A, Goncalves IC et al. Effect of surface chemistry on bacterial adhesion, viability, and morphology. J. Biomed. Mater. Res. A 99(3), 344-353 (2011).

31 Andersson DI, Hughes D. Antibiotic resistance and its cost: is it possible to reverse resistance? Nat. Rev. Microbiol. 8(4), 260-271 (2010).

32 Levin BR, Rozen DE. Non-inherited antibiotic resistance. Nat. Rev. Microbiol. 4(7), 556-562 (2004).

33 Schwaber MJ, De-Medina T, Carmeli Y. Epidemiological interpretation of antibiotic resistance studies - what are we missing? Nat. Rev. Microbiol. 2(12), 979-983 (2004).

34 Levy SB, Marshall B. Antibacterial resistance worldwide: causes, challenges and responses. Nat. Med. 10, 122-129 (2004).

35 Characklis WG. Bioengineering report: fouling biofilm development: a process analysis. Biotechnol. Bioeng. 23(9), 1923-1960 (1981).

36 Jendresen MD, Glantz PO, Baier RE, Eick JD. Microtopography and clinical adhesiveness of an acid etched tooth surface. An in-vivo study. Acta Odontol. Scand. 39(1), 47-53 (1981).

37 Skjørland KK, Hensten-Pettersen A, Ørsta-Vik D, Söderholm K-J. Tooth colored dental restorative materials: porosities and surface topography in relation to bacterial adhesion. Acta Odontol. Scand. 40(2), 113-120 (1982).

38 Absolom DR, Lamberti FV, Policova Z et al. Surface thermodynamics of bacterial adhesion. Appl. Environ. Microbiol. 46(1), 90-97 (1983).

39 Jacobsen PH, Robinson PB. Basic techniques and materials for conservative dentistry. 2 . Recent advances in restorative materials. J. Dent. 9(2), 95-100 (1981).

40 Razatos A, Ong YL, Sharma MM, Georgiou G. Molecular determinants of bacterial adhesion monitored by atomic force microscopy. Proc. Natl Acad. Sci. USA 95(19), 11059-11064 (1998).

-1" First application of a nanotechnology-based method (atomic force microscopy) to quantify the adhesion forces between bacteria and abiotic surfaces.

41 Dai X, Schalek R, Xu Q. Staining and etching: a simple method to fabricate inorganic nanostructures from tissue slices. Adv. Mater. 24(3), 370-374 (2012).

42 Hatsuki R, Yamamoto T. Nanoscale etching and flattening of metals with ozone water. Nano Lett. 12(6), 3158-3161 (2012).

43 Naderi N, Hashim MR. A combination of electroless and electrochemical etching methods for enhancing the uniformity of porous silicon substrate for light detection application. Appl. Surf. Sci. 258(17), 6436-6440 (2012).

44 Bakker DP, Busscher HJ, Van Zanten J et al. Multiple linear regression analysis of bacterial deposition to polyurethane coatings after conditioning film formation in the marine environment. Microbiology $150(\mathrm{Pt}$ 6), 1779-1784 (2004).

45 Whitehead KA, Colligon J, Verran J. Retention of microbial cells in substratum surface features of micrometer and submicrometer dimensions. Colloids Surf. B Biointerfaces 41(2-3), 129-138 (2005).

46 Campoccia D, Montanaro L, Agheli $\mathrm{H}$ et al. Study of Staphylococcus aureus adhesion on a novel nanostructured surface by chemiluminometry. Int. J. Artif. Organs 29(6), 622-629 (2006).

47 Díaz C, Schilardi PL, Salvarezza RC, De Mele MF. Nano/microscale order affects the early stages of biofilm formation on metal surfaces. Langmuir 23(22), 11206-11210 (2007).

48 Edwards KJ, Rutenberg AD. Microbial response to surface microtopography: the role of metabolism in localized mineral dissolution. Chem. Geol. 180(1-4), 19-32 (2001).

49 Puckett SD, Taylor E, Raimondo T, Webster TJ. The relationship between the nanostructure of titanium surfaces and bacterial attachment. Biomaterials 31(4), 706-713 (2010).

50 Durmus NG, Taylor EN, Inci F et al. Fructose-enhanced reduction of bacterial growth on nanorough surfaces. Int. J. Nanomedicine 7, 537-545 (2012).

51 Mitik-Dineva N, Wang J, Mocanasu RC et al. Impact of nano-topography on bacterial attachment. Biotechnol. J. 3(4), 536-544 (2008).

52 Mitik-Dineva N, Wang J, Truong VK et al. Differences in colonization of five marine bacteria on two types of glass surfaces. Biofouling 25(7), 621-631 (2009).

53 Loo CY, Young PM, Lee WH et al. Superhydrophobic, nanotextured polyvinyl chloride films for delaying Pseudomonas aeruginosa attachment to intubation tubes and medical plastics. Acta Biomater. 8(5), 1881-1890 (2012).
54 Tang H, Cao T, Liang X et al. Influence of silicone surface roughness and hydrophobicity on adhesion and colonization of Staphylococcus epidermidis. J. Biomed. Mater. Res. A 88(2), 454-463 (2009).

55 Quirynen M, Van Der Mei HC, Bollen CML et al. The influence of surface-free energy on supra- and subgingival plaque microbiology. An in vivo study on implants. J. Periodontol. 65(2), 162-167 (1994).

56 Sousa C, Teixeira P, Oliveira R. Influence of surface properties on the adhesion of Staphylococcus epidermidis to acrylic and silicone. Int. J. Biomater. 2009, 1-9 (2009).

57 Liu Y, Zhao Q. Influence of surface energy of modified surfaces on bacterial adhesion. Biophys. Chem. 117(1), 39-45 (2005).

58 Katsikogianni M, Amanatides E, Mataras D, Missirlis YF. Staphylococcus epidermidis adhesion to $\mathrm{He}, \mathrm{He} / \mathrm{O}(2)$ plasma treated PET films and aged materials: contributions of surface free energy and shear rate. Colloids Surf. B Biointerfaces 65 (2), 257-268 (2008).

59 Almaguer-Flores A, Olivares-Navarrete R, Wieland Met al. Influence of topography and hydrophilicity on initial oral biofilm formation on microstructured titanium surfaces in vitro. Clin. Oral Implants Res. 23(3), 301-307 (2012)

60 Anselme K, Davidson P, Popa AM et al. The interaction of cells and bacteria with surfaces structured at the nanometre scale. Acta Biomater. 6(10), 3824-3846 (2010).

61 Gentile F, Tirinato L, Battista E et al. Cells preferentially grow on rough substrates. Biomaterials 31(28), 7205-7212 (2010).

62 Ivanova EP, Pham DK, Wright JP, Nicolau DV. Detection of coccid forms of Sulfitobacter mediterraneus using atomic force microscopy. FEMS Microbiol. Lett. 214(2), 177-181 (2002).

63 Tang J, Zhang Q, Zeng Q, Man SH. Preparation of large-area surface-enhanced Raman scattering active $\mathrm{Ag}$ and $\mathrm{Ag} / \mathrm{Au}$ nanocomposite films. Appl. Phys. A doi:10.1007/s00339-013-7568-7568 (2013) (Epub ahead of print)

64 Leefmann T, Heim C, Siljeström S et al. Spectral characterization of ten cyclic lipids using time-of-flight secondary ion mass spectrometry. Rapid Commun. Mass Spectrom. 27(5), 565-581 (2013)

65 Vadillo-Rodriguez V, Logan BE. Localized attraction correlates with bacterial adhesion to glass and metal oxide substrata. Environ. Sci. Technol. 40(9), 2983-2988 (2006).

66 Popham DL, Young KD. Role of penicillin-binding proteins in bacterial cell morphogenesis. Curr. Opin. Microbiol. 6(6), 594-599 (2003). 
67 Thanassi DG, Hultgren SJ. Multiple pathways allow protein secretion across the bacterial outer membrane. Curr. Opin. Cell Biol. 12(4), 420-430 (2000).

68 Jefferson KK. What drives bacteria to produce a biofilm? FEMS Microbiol. Lett. 236(2), 163-173 (2004).

69 Smyth CJ, Marron MB, Twohig JM, Smith SG. Fimbrial adhesins: similarities and variations in structure and biogenesis. FEMS Immunol. Med. Microbiol. 16(2), 127-139 (1996).

70 Rizzello L, Sorce B, Sabella S et al. Impact of nanoscale topography on genomics and proteomics of adherent bacteria. ACS Nano 5(3), 1865-1876 (2011).

" $\quad$ First demonstration that surface nanoroughness induces specific genomic and proteomic variations in adherent bacteria.

71 Rizzello L, Galeone A, Vecchio G et al. Molecularresponse of Escherichia coli adheringonto nanoscale topography. Nanoscale Res. Lett. 7, 575 (2012).

72 Rizzello L, Shankar SS, Fragouli D et al. Microscale patterning of hydrophobic/ hydrophilic surfaces by spatially controlled galvanic displacement reactions. Langmuir 25(11), 6019-6023 (2009).

73 Shankar SS, Rizzello L, Cingolani R, Rinaldi R, Pompa PP. Micro/nanoscale patterning of nanostructured metal substrates for plasmonic applications. ACS Nano 3(4), 893-900 (2009).

74 Blattler T, Huwiler C, Ochsner M et al. Nanopatterns with biological functions. J. Nanosci. Nanotechnol. 6(8), 2237-2264 (2006).

75 Truskett VN, Watts MP. Trends in imprint lithography for biological applications. Trends Biotechnol. 24(7), 312-317 (2006).

76 Wood MA. Colloidal lithography and current fabrication techniques producing in-plane nanotopography for biological applications. J. R. Soc. Interface 4(12), 1-17 (2007).

77 Oh S, Brammer KS, Li YS et al. Stem cell fate dictated solely by altered nanotube dimension. Proc. Natl Acad. Sci. USA 106(7), 2130-2135 (2009).

78 Renault JP, Bernard A, Bietsch A et al. Fabricating arrays of single protein molecules on glass using microcontactprinting. J. Phys. Chem. B 107(3), 703-711 (2002).

79 Ginger DS, Zhang H, Mirkin CA. The evolution of dip-pen nanolithography. Angew. Chem. Int. Ed. Engl. 43(1), 30-45 (2004).

80 Hou S, Burton EA, Simon KA et al. Inhibition of Escherichia coli biofilm formation by self-assembled monolayers of functional alkanethiols on gold. Appl. Environ. Microbiol. 73(13), 4300-4307 (2007).
81 Hou S, Gu H, Smith C, Ren D. Microtopographicpatterns affect Escherichia coli biofilm formation on poly(dimethylsiloxane) surfaces. Langmuir 27(6), 2686-2691 (2011).

82 Hochbaum AI, Aizenberg J. Bacteria pattern spontaneously on periodic nanostructure arrays. Nano Lett. 10(9), 3717-3721 (2010).

"II Demonstrates that nanometer-scale periodic surface features are able to orient bacterial attachment at the single-cell level.

83 Díaz C, Schilardi PL, Salvarezza RC, Fernandez Lorenzo De Mele M. Have flagella a preferred orientation during early stages of biofilm formation? AFM study using patterned substrates. Colloids Surf. B Biointerfaces 82(2), 536-542 (2011).

84 Weibel DB, DiLuzio WR, Whitesides GM. Microfabrication meets microbiology. Nat. Rev. Microbiol. 5, 209 (2007).

85 Scheuerman TR, Camper AK, Hamilton MA. Effects of substratum topography on bacterial adhesion. J. Colloid Interface Sci. 208(1), 23-33 (1998).

86 Liau SY, Read DC, Pugh WJ, Furr JR, Russell AD. Interaction of silver nitrate with readily identifiable groups: relationship to the antibacterial action of silver ions. Lett. Appl. Microbiol. 25(4), 279-283 (1997).

87 Silver S. Bacterial silver resistance: molecular biology and uses and misuses of silver compounds. FEMS Microbiol. Rev. 27(2-3), 341-353 (2003)

88 Klasen HJ. A historical review of the use of silver in the treatment of burns. II. Renewed interest for silver. Burns 26(2), 131-138 (2000)

89 Bajpai SK, Mohan YM, Bajpai M, Tankhiwale R, Thomas V. Synthesis of polymer stabilized silver and gold nanostructures. J. Nanosci. Nanotechnol. 7(9), 2994-3010 (2007).

90 Kong H, Jang J. Antibacterial properties of novel poly(methyl methacrylate) nanofiber containing silver nanoparticles. Langmuir 24(5), 2051-2056 (2008).

91 Sharma VK, Yngard RA, Lin Y. Silver nanoparticles: green synthesis and their antimicrobial activities. Adv. Colloid Interface Sci. 145(1-2), 83-96 (2009).

92 Thomas V, Jayabalan M. A new generation of high flex life polyurethane urea for polymer heart valve - studies on in vivo biocompatibility and biodurability. J. Biomed. Mater. Res. A 89(1), 192-205 (2009)

93 Vimala K, Mohan YM, Sivudu KS et al. Fabrication of porous chitosan films impregnated with silver nanoparticles: a facile approach for superior antibacterial application. Colloids Surf. B Biointerfaces 76(1), 248-258 (2010).

94 Juby KA, Dwivedi C, Kumar M et al. Silver nanoparticle-loaded PVA/gum acacia hydrogel: synthesis, characterization and antibacterial study. Carbohyd. Polym. 89(3), 906-913 (2012).

95 Vasilev K, Sah V, Anselme K et al. Tunable antibacterial coatings that support mammalian cell growth. Nano Lett. 10(1), 202-207 (2010).

96 Morones JR, Elechiguerra JL, Camacho A et al. The bactericidal effect of silver nanoparticles. Nanotechnology 16(10), 2346-2353 (2005)

97 Sondi I, Salopek-Sondi B. Silver nanoparticles as antimicrobial agent: a case study on E. coli as a model for Gram-negative bacteria. J. Coll. Interf. Sci. 275(1), 177-182 (2004).

98 Lok CN, Ho CM, Chen R. Proteomic analysis of the mode of antibacterial action of silver nanoparticles. J. Proteome Res. 5(4), 916-924 (2006).

99 Xiu ZM, Zhang QB, Puppala HL, Colvin VL, Alvarez PJJ. Negligible particle-specific antibacterial activity of silver nanoparticles. Nano Lett. 12(8), 4271-4275 (2012).

" First demonstration that silver nanoparticles elicit bactericidal effects due to the release of $\mathrm{Ag}^{+}$ions from their surface.

100 Park HJ, Kim JY, Kim J et al. Silver-ionmediated reactive oxygen species generation affecting bactericidal activity. Water Res. 43(4) 1027-1032 (2009).

101 Inoue $\mathrm{Y}$, Hoshino $\mathrm{M}$, Takahashi $\mathrm{H}$ et al. Bactericidal activity of $\mathrm{Ag}$-zeolite mediated by reactive oxygen species under aerated conditions. J. Inorg. Biochem. 92(1), 37-42 (2002).

102 Le Pape H, Solano-Serena F, Contini P et al. Involvement of reactive oxygen species in the bactericidal activity of activated carbon fibre supporting silver: bactericidal activity of ACF $(\mathrm{Ag})$ mediated by ROS. J. Inorg. Biochem. 98(6), 1054-1060 (2004).

103 Oertel G. Polyurethane Handbook: Chemistry, Raw Materials, Processing, Application, Properties. Hanser Gardner Publications, $\mathrm{OH}$, USA (1994).

104 Shah MSAS, Nag M, Kalagara T, Singh S, Manorama SV. Silver on PEG-PU-TiO, polymer nanocomposite films: an excellent system for antibacterial applications. Chem. Mater. 20(7), 2455-2460 (2008).

105 Melaiye A, Sun Z, Hindi K et al. Silver(I)-imidazole cyclophane gem-diol complexes encapsulated by electrospuntecophilicnanofibers: formation of nanosilver particles and antimicrobial activity. J. Am. Chem. Soc. 127(7), 2285-2291 (2005). 
106 Kaplan DL. Biopolymers from Renewable Resources. Springer-Verlag Berlin Heidelberg, NY, USA (1998).

107 Fullenkamp DE, Rivera JG, Gong YK et al. Mussel-inspired silver-releasing antibacterial hydrogels. Biomaterials 33(15), 3783-3791 (2012).

108 Rattanaruengsrikul V, Pimpha N, Supaphol P. In vitro efficacy and toxicology evaluation of silver nanoparticle-loaded gelatin hydrogel pads as antibacterial wound dressings. J. Appl. Polym. Sci. 124(2), 1668-1682 (2012).

109 Bayer IS, Fragouli D, Attanasio A et al. Water-repellent cellulose fiber networks with multifunctional properties. ACS Appl. Mater. Interfaces 3(10), 4024-4031 (2011).
110 Nadagouda MN, Varma RS. Synthesis of thermally stable carboxymethyl cellulose/ metal biodegradable nanocomposites for potential biological applications. Biomacromolecules 8(9), 2762-2767 (2007).

111 Klemm D, Heublein B, Fink HP, Bohn A Cellulose: fascinating biopolymer and sustainable raw material. Angew. Chem. Int. Ed. Engl. 44(22), 3358-3393 (2005).

112 Czaja WK, Young DJ, Kawecki M, Brown RM. The future prospects of microbial cellulose in biomedical applications. Biomacromolecules 8(1), 1-12 (2007).

"- Collates the current knowledge on cellulose and all its foreseeable broad applications.

113 Cranston ED, Gray DG. Morphological and optical characterization of polyelectrolyte multilayers incorporating nanocrystalline cellulose. Biomacromolecules 7(9), 2522-2530 (2006).

114 Travan A, Pelillo C, Donati I et al. Noncytotoxic silver nanoparticle-polysaccharide nanocomposites with antimicrobial activity. Biomacromolecules 10(6), 1429-1435 (2009).

115 Mayer C, Moritz R, Kirschner C et al. The role of intermolecular interactions: studies on model systems for bacterial biofilms. Int. J. Biol. Macromol. 26(1), 3-16 (1999).

\section{Website}

201 The Leptospirosis Information Center. www.leptospirosis.org 